\title{
PENERAPAN MODEL ARBITRAGE PRICING THEORY DENGAN PENDEKATAN VECTOR AUTOREGRESSION DALAM MENGESTIMASI EXPECTED RETURN SAHAM (Studi Kasus: Saham-Saham Kompas100 Periode 2010-2013)
}

\author{
Vian Riska AyUning Tyas ${ }^{1}$, Komang DharmaWan ${ }^{2}$, MAde Asih $^{3}$ \\ 1,2,3 Jurusan Matematika FMIPA Universitas Udayana, Bukit Jimbaran-Bali \\ e-mail: ${ }^{1}$ vianriska21@gmail.com, ${ }^{2}$ dharmawan.komang@gmail.com, \\ 3asihmath77@gmail.com
}

\begin{abstract}
The Arbitrage Pricing Theory (APT) is an alternative model to estimate the price of securities based of arbitrage concept. In APT, the returns of securities are affected by several factors. This research is aimed to estimate the expected returns of securities using APT model and Vector Autoregressive model. There are ten stocks incorporated in Kompas100 index and four macroeconomic variables, these are inflation, exchange rates, the amountof circulate money (JUB), and theinterest rateof Bank Indonesia(SBI) are applied in this research.

The first step in using VAR is to test the stationary of the data using colerogram and the results indicate that all data are stationary. The second step is to select the optimal lag based on the smallest value of AIC. The Granger causality test shows that the LPKR stock is affected by the inflation and the exchange rate while the nine other stocks do not show the existence of the expected causality. The results of causality test are then estimated by the VAR models in order to obtain expected returnof macroeconomic factors. The expected return of macroeconomic factors obtained is used in the APT model, then the expected return stock LPKR is calculated. It shows that the expected return of LPKR is 3,340\%
\end{abstract}

Keywords: Arbitrage Pricing Theory, Granger causality test, optimal lag test, Portmanteau test, stationary test, Vector Autoregression

\section{Pendahuluan}

Investasi merupakan salah satu alternatif untuk meningkatkan nilai aset pada masa depan sehingga dengan melakukan investasi, penurunan daya beli dapat diimbangi dengan return dari investasi. Pada dunia investasi terdapat suatu risiko dan untuk meminimalkannya investor akan mengestimasi tingkat pengembalian yang diharapkan (expected return). Metode yang biasa digunakan untuk mengestimasi expected return salah satunya adalah Arbitrage Pricing Theory (APT).

APT menyatakan tingkat pengembalian saham berhubungan linear dengan $n$ faktor. APT tidak menyebutkan faktor-faktor tersebut, namun diasumsikan bahwa tingkat pengembalian saham dan faktor-faktor tersebut memiliki hubungan yang linear (Fabozzi, F.J., 1999).

Faktor-faktor dalam APT dapat diartikan sebagai variabel-variabel makroekonomi yang memengaruhi pergerakan harga saham. Untuk melihat pengaruh dan hubungan kausalitas antara return saham dan variabel-variabel makroekonomi dapat digunakan analisis Vector Autoregression (VAR).

Salah satu keunggulan VAR adalah bahwa model VAR ini sederhana, peneliti tidak perlu menentukan mana variabel endogen dan mana variabel eksogen karena semua variabel dalam

\footnotetext{
${ }^{1}$ Mahasiswa Jurusan Matematika FMIPA Universitas Udayana

${ }^{2}$ Staf Pengajar Jurusan Matematika FMIPA Universitas Udayana
} 
VAR adalah variabel endogen. Selain itu VAR dapat dibuat model terpisah untuk masing-masing variabel endogen. Hasil peramalan (forecast) dengan model ini pada banyak kasus lebih baik dibandingkan dengan hasil peramalan yang diperoleh dengan menggunakan model persamaan simultan yang komplek (Gujarati, 2003).

\section{Ulasan Pustaka}

\section{Arbitrage Pricing Theory (APT)}

Arbitrage Pricing Theory (APT) merupakan model alternatif untuk menentukan harga saham yang sepenuhnya berdasarakan konsep arbitrase, sehingga disebut teori penetapan harga arbitrase (Arbitrage Pricing Theory). Secara sederhana, arbitrase berarti pembelian dan penjualan saham yang berkarakteristik sama pada pasar yang berbeda (Fabozzi, F.J., 1999).

Model APT memiliki asumsi bahwa tingkat pengembalian acak atas sekuritas $i$ dipengaruhi oleh beberapa faktor. Asumsi tersebut dapat dinyatakan dalam persamaan sebagai berikut:

$\tilde{R}_{i}=E\left(R_{i}\right)+\beta_{i .1} \widetilde{F}_{1}+\cdots+\beta_{i . n} \tilde{F}_{n}+\tilde{\epsilon}_{i}$

dengan $\tilde{R}_{i}$ menyatakan tingkat pengembalian acak dari sekuritas $i, E\left(R_{i}\right)$ menyatakan pengembalian yang diharapkan dari sekuritas $i$, $\beta_{i . n}$ menyatakan kepekaan sekuritas ke- $i$ terhadap faktor ke- $n, \widetilde{F}_{1}$ menyatakan faktor ke$n$ yang umum bagi pengembalian sekuritas, dan $\tilde{\epsilon}_{i}$ menyatakan pengembalian tidak sistematis bagi sekuritas.

Persamaan APT dapat digeneralisasikan ke dalam kondisi di mana terdapat faktor $n$, sehingga menjadi:

$$
\begin{aligned}
E\left(R_{i}\right)= & R_{F}+\beta_{1, F 1}\left[E\left(R_{F 1}\right)-R_{F}\right] \\
& +\beta_{2, F 2}\left[E\left(R_{F 2}\right)-R_{F}\right]+\cdots \\
& +\beta_{n, F n}\left[E\left(R_{F n}\right)-R_{F}\right] .
\end{aligned}
$$

Model ini menyatakan bahawa investor ingin memperoleh kompensasi atas seluruh faktor yang secara matematis mempengaruhi pengembalian sekuritas. Kompensasi itu adalah jumlah dari hasil setiap risisko sistematis dan premi risisko diberikan oleh faktor pasar keuangan $\beta_{1, F 2}\left[E\left(R_{F 2}\right)-R_{F}\right]$. Dalam model risiko dan pengembalian lain dijelaskan, investor tidak memperoleh kompensasi atas risiko tidak sistematis yang diterimanya (Fabozzi, F.J., 1999).

\section{Variabel-Variabel Makroekonomi}

Variabel-variabel makroekonomi dapat dijadikan faktor-faktor dalam APT. APT menyatakan bahwa harga saham dipengaruhi oleh berbagai faktor. Karena variabel-variabel makroekonomi berpengaruh terhadap harga saham maka variabel-variabel makroekonomi dapat dijadikan faktor-faktor dalam APT.

Menurut Mankiw (2007) menjelaskan bahwa inflasi, kurs, suku bunga, dan jumlah uang yang beredar merupakan variabel-variabel makroekonomi yang berpengaruh terhadap harga saham. Oleh karena itu dalam penelitian ini digunakan empat variabel makroekonimi tersebut.

Faktor-faktor makroekonomi yang akan digunakan dalam penelitian ini adalah sebagai berikut:

1. Inflasi

2. Nilai Tukar Mata Uang (Kurs)

3. Jumlah Uang Beredar (JUB)

4. Suku Bunga Bank Indonesia (SBI)

\section{Vector Autoregression}

Vector Autoregressive (VAR) merupakan analisis yang biasanya digunakan dalam menganalisis hubungan variabel-variabel deret waktu. Perbedaan analisis VAR dengan analisis deret waktu yang lain terletak pada model persamaan simultannya karena dalam analisis ini mempertimbangkan beberapa variabel endogen (terikat) secara bersamasama dalam suatu model. Masing-masing masing variabel selain diterangkan oleh nilainya di massa lampau juga dipengaruhi oleh nilai masa lalu dari semua variabel endogen lainnya dalam model yang diamati.

Menurut Tsay (2002), suatu data deret waktu multivariat $\mathrm{X}_{t}$ merupakan suatu proses 
VAR orde satu atau $\operatorname{VAR}(1)$, jika mengikuti model:

$$
\mathrm{X}_{t}=\delta+\theta \mathrm{X}_{t-1}+u_{t}
$$

dengan $\delta$ merupakan suatu vektor dimensi $k, \theta$ merupakan matriks $k \times k$, dan $u_{t}$ merupakan vektor acak yang tidak saling berkorelasi, rataannya nol dan kovarians berupa matriks dilambangkan $\Sigma$. Misal $x_{1 t}$ dan $x_{2 t}$ dimasukkan ke dalam persamaan VAR orde satu, maka persamaan VAR dapat dinyatakan sebagai:

$x_{1 t}=\delta_{11}+\theta_{11} x_{1 t-1}+\theta_{12} x_{2 t-1}+u_{1 t}$,

$x_{2 t}=\delta_{21}+\theta_{21} x_{1 t-1}+\theta_{22} x_{2 t-1}+u_{2 t}$.

Asumsi yang harus dipenuhi dalam analisis VAR adalah semua variabel terikat bersifat stasioner, semua residual bersifat white noise, yaitu memiliki rataan nol, varians konstan dan tidak terdapat korelasi di antara variabel terikat.

\section{Kestasioneran Data}

Data yang stasioner merupakan data yang berada dalam kesetimbangan di sekitar nilai yang konstan dan varians di sekitar rataan tersebut tetap konstan selama periode waktu tertentu (Mankiw, 2007).

Pola data deret waktu dapat dilihat dari plot atau grafik data tersebut dan untuk mengetahui apakah data deret waktu stasioner atau tidak, maka dapat dilihat dari korelogram. Data deret waktu dikatakan tidak stasioner apabila plot autokorelasi berada di luar garis Bartlet (garis putus-putus), nilai koefisien autokorelasi pada lag satu cukup besar, dan turun secara perlahan [3], serta nilai probabilitas yang mendekati nol atau lebih kecil dari 5\% (Winarno, 2007).

\section{Lag Optimal}

Sebelum melakukan analisis VAR perlu dilakukan pemeriksaan lag yang optimal terlebih dahulu. Pemeriksaan lag digunakan untuk menentukan panjang lag optimal yang akan digunakan dalam estimasi hubungan kausalitas dan akan menentukan estimasi parameter untuk model VAR. Estimasi hubungan kausalitas dan model VAR sangat peka terhadap panjang lag, sehingga perlu untuk menentukan ketepatan panjang lag yang optimal (Widarjono, 2007). Untuk menentukan panjang lag optimal pada model VAR dapat menggunakan Akaike Information Criteria (AIC). Perhitungan untuk AIC adalah :

$$
A I C=\ln \left(\frac{R S S}{n}\right)+\frac{2 k}{n}
$$

dengan RSS adalah banyak residual kuadrat (residual sum of squares), $k$ adalah banyak parameter yang diestimasi dan $n$ adalah banyak observasi.Lag optimal ada pada nilai terkecil yang didapat dari perhitungan AIC (Widarjono, 2007).

\section{Kausalitas Granger}

Salah satu analisis yang berkaitan dengan model VAR adalah mencari hubungan sebab akibat atau uji kausalitas antarvariabel endogen (dependent/terikat) di dalam model VAR.Hubungan sebab akibat ini bisa diuji menggunakan uji kausalitas Granger (Widarjono, 2007).

Menurut Rosadi (2012), untuk menjelaskan konsep kausalitas Granger berikut digunakan kasus dua variabel runtun waktu yang stasioner misal $X$ dan $Y$ dapat dinyatakan dengan persamaan restricted sebagai berikut:

$$
Y_{t}=\alpha+\phi_{1} Y_{t-1}+\beta_{1} X_{t-1}+\varepsilon_{t}(6)
$$

dengan $Y_{t}$ adalah nilai variabel $Y$ pada saat periode waktu ke $t, \quad Y_{t-1}$ adalah nilai variabel $Y$ pada saat periode waktut $-1, \alpha$ adalah intersep, $\phi_{1}$ koefisien dari lag ke-1 variabel $Y, X_{t-1}$ adalah nilai variabel $X$ pada saat periode waktu $t-1, \beta_{1}$ adalah koefisien dari lag ke-1 variabel $X$, dan $\varepsilon_{t}$ galat pada saat $t$

Persamaan (6) dapat digeneralisasikan menjadi persamaan yang lebih umum yaitu persamaan unrestricted sebagai berikut: 


$$
\begin{array}{r}
Y_{t}=\alpha+\delta_{t}+\phi_{1} Y_{t-1}+\cdots+\phi_{p} Y_{p-1}+ \\
\beta_{1} X_{t-1}+\cdots+\beta_{q} X_{q-1}+\cdots+\varepsilon_{t}(7)
\end{array}
$$

dengan $Y_{t}$ adalah nilai variabel $Y$ pada saat periode waktu ke $t, \alpha$ adalah intersep, $Y_{t-1}$ adalah nilai variabel $Y$ pada saat periode waktu $t-1, \phi_{1}$ koefisien dari lag ke1 variabel $Y, \phi_{p}$ adalah koefisien dari lag ke $p$ variabel $Y, Y_{p-1}$ adalah nilai variabel $Y$ pada saat $p-1, X_{t-1}$ adalah nilai variabel $X$ pada saat periode waktu $t-1, \beta_{1}$ adalah koefisien dari lag ke-1 variabel $X, \beta_{q}$ adalah koefisisen, dari lag ke- $q$ variabel $X, \quad X_{q-1}$ adalah nilai variabel $X$ pada saat $q-1$, dan $\varepsilon_{t}$ adalah galat pada saat $t$.

Persamaan (7) dapat dinyatakan $X$ Granger cause $Y$ jika terdapat setidaknya satu $\beta_{i}, i=1,2, \ldots, q$ yang signifikan. Estimasi model dapat dilakukan dengan metode metode Ordinary Least Square (OLS) dan uji signifikansi koefisien regresi dilakukan dengan uji statistik F.

Koefisien $\beta_{1}$ dalam persamaan mengukur besarnya pengaruh $X_{t-1}$ terhadap $Y_{t}$. Dengan demikian jika nilai $\beta_{1}=0$ maka $X$ tidak granger cause $Y$. Pengujian kausalitas Granger untuk persamaan (7) dapat dilakukan dengan uji signifikansi parameter dengan menggunakan metode Ordinary Least Square (OLS) dan uji signifikansi menggunakan metode standar yaitu uji F. Uji $F$ dapat dihitung dengan menggunakan persamaan sebagai berikut:

$$
F=(n-k) \frac{R S S_{R}-R S S_{U R}}{m\left(R S S_{U R}\right)}
$$

dengan $R S S_{R}$ adalah nilai jumlah kuadrat residual dalam persamaan restricted, $R S S_{U R}$ adalah nilai jumlah kuadrat residual dalam persamaan unrestricted, $n$ adalah banyak observasi, $m$ adalah banyak lag, dan $k$ adalah banyak parameter yang diestimasi di dalam persamaan unrestricted.

\section{Uji Diagnostik Portmanteau}

Uji diagnostik dilakukan untuk memenuhi asumsi white noise. Dalam penelitian ini, uji diagnostik yang digunakan adalah Uji. Uji ini pertama kali diperkenalkan oleh Box dan Pierce pada tahun 1970. Uji Portmanteau menghasilkan statistik $Q$ yang mengikuti sebaran chi square dengan persamaan sebagai berikut:

$$
Q=n \sum_{k=1}^{m}\left(r_{k}\right)^{2}(9)
$$

dengan Q adalah Statistik Q, $n$ adalah banyaknya peubah yang digunakan, $k=$ $1, \ldots, m$ adalah beda kala (lag), dan $r_{k}$ adalah residual autokorelasi. Sedangkan hipotesis yang akan diuji adalah sebagai berikut:

$H_{0}=$ tidak ada autokorelasi sisaan sampai lag ke-m

$H_{1}=$ terdapat autokorelasi sisaan sampai lag ke$m$

jika nilai probabilitas dari statistik Q lebih besar dari 0.1 maka terima $H_{0}$ yang berarti tidak terdapat autokorelasi yang signifikan hingga lag yang ditentukan.

\section{Metode Penelitian}

Data yang digunakan pada penelitian ini adalah data sekunder berupa data variabelvariabel ekonomi seperti tingkat inflasi, tingkat suku bunga SBI, nilai tukar mata uang Rupiah terhadap Dollar Amerika dan jumlah uang yang beredar di Indonesia, berupa data bulanan dari tahun (2010-2013) yang dapat diperoleh pada situs www.bi.go.id. Data sepuluh indeks harga saham perusahaan-perusahaan yang tergabung dalam bursa saham Kompas100 diperoleh dari situs www.yahoo.finance.com berupa data bulanan dari tahun (2010-2013).

Langkah-langkah analisis dalam penelitian ini meliputi:

1. Pemilihan sepuluh saham yang tergabung dalam Kompas100 menggunakan kriteria sebagai berikut:

a. Saham yang selalu tergabung dalam bursa saham Kompas100 selama periode tahun 2010 hingga tahun 2013.

b. Saham yang memiliki volume perdagangan tinggi selama periode 
penelitian yang dihitung berdasarkan rata-rata volume perdagangan dengan rumus sebagai berikut:

$$
\bar{x}=\frac{\sum_{i=1}^{n} x_{i}}{n}
$$

dengan $\bar{x}$ adalah rata-rata hitung, $n$ adalah jumlah data, dan $x_{i}$ adalah nilai data ke- $i$.

2. Langkah awal dalam menentukan expected return suatu saham adalah menghitung return saham dan return variabel makroekonomi (return faktor) terlebih dahulu. Perhitungan return masing-masing saham menggunakan persamaan sebagai berikut:

$$
R_{i, t}=\frac{P_{i, t}-P_{i, t-1}}{P_{i, t-1}}
$$

3. Arbitrage Pricing Theory menyatakan return saham berhubungan linier dengan $n$ faktor (variable-variabel makroekonomi) sehingga perlu menghitungreturn faktor makroekonomi.

4. Uji Stasioneritas

5. Uji lag optimal dengan memilih nilai AIC yang terkecil

6. Uji kausalitas Granger

7. Menentukan model VAR

8. Uji Diagnostik Portmanteau

9. Estimasi dengan Model VAR

10. Menyusun Persamaan APT

11. Menghitung expected return saham

\section{Hasil dan Pembahasan}

Penelitian ini menggunakan sepuluh saham pada Kompas100 sebagai sampel, Dalam menentukan sepuluh saham tersebut digunakan dua kriteria. Kriteria yang pertama adalah saham yang selalu tergabung pada Kompas 100 dalam periode penelitian yaitu 2010-2013 sehingga ada sembilan kali evaluasi yang terjadi. Pada periode penelitian tersebut terdapat 46 saham yang selalu bertahan dalam Kompas100. Selanjutnya untuk memperoleh kriteria yang kedua, saham-saham tersebut diperingkat berdasarkan rata-rata volume perdagangan saham dan dipilih sepuluh saham dengan rata-rata volume perdagangan paling tinggi. Perhitungan rata-rata volume perdagangan saham dihitung menggunakan persamaan (10).

Sepuluh saham tersebut adalah Telekomunikasi Idonesia (TLKM), Sentul City (BKSL), Kalbe Farma (KLBF), Alam Sutera Realty (ASRI), Jasa Marga (JSMR), Lippo Karawaci (LPKR), Bhakti Investama (BHIT), Kawasan Industri Jababeka (KIJA), Bakrie Sumatra Planstations (UNSP), dan Adaro Energi (ADRO). Selanjutnya dihitung masingmasing return dari kesepuluh saham tersebut. Rata-rata return sepuluh saham tersebut dapat dilihat pada tabel berikut:

Tabel 1. Daftar Sepuluh Saham Kompas100 Periode 2010-2013

\begin{tabular}{|c|c|c|}
\hline No & Kode Saham & Rata-Rata \\
\hline 1 & TLKM & $-0,01794$ \\
\hline 2 & BKSL & 0,05336 \\
\hline 3 & KLBF & 0,05707 \\
\hline 4 & ASRI & 0,03872 \\
\hline 5 & JSMR & 0,03051 \\
\hline 6 & LPKR & 0,03084 \\
\hline 7 & BHIT & 0,02111 \\
\hline 8 & KIJA & 0,02819 \\
\hline 9 & UNSP & 0,00765 \\
\hline 10 & ADRO & $-0,04742$ \\
\hline
\end{tabular}

Variabel-variabel makroekonomi dalam penelitian ini merupakan faktor-faktor yang dianggap memengaruhi return saham Kompas100. Tingkat pengembalian variabelvariabel makroekonomi yang digunakan untuk mengestimasi return saham disebut juga return faktor dalam APT. Oleh karena itu setelah menghitung return saham langkah selanjutnya adalah menghitung return faktor. Rata-rata return faktor dapat dilihat pada Tabel 2: 
Tabel 2. Rata-Rata Return Faktor

\begin{tabular}{|c|l|c|}
\hline $\begin{array}{c}\text { N } \\
\text { o }\end{array}$ & \multicolumn{1}{|c|}{ Return Faktor } & $\begin{array}{l}\text { Rata- } \\
\text { Rata }\end{array}$ \\
\hline 1 & Inflasi & $-0,11589$ \\
\hline 2 & Nilai Tukar Mata Uang (Kurs) & 0,00260 \\
\hline 3 & Jumlah Uang Beredar (JUB) & 0,01318 \\
\hline & $\begin{array}{l}\text { Suku Bunga Bank Indonesia } \\
\text { (SBI) }\end{array}$ & 0,00022 \\
\hline
\end{tabular}

\section{Uji Stasioneritas}

Uji kestasioneran data dilakukan terlebih dahulu sebelum melakukan analisis VAR untuk menghindari hasil regresi palsu dan melihat kestasioneran data. Untuk menguji kestasioneran data dalam penelitian ini menggunakan korelogram. Berdasarkan plot series dan korelogram dipereroleh hasil uji stasioner sepuluh return saham dan return faktor makroekonomi mempunyai data yang sudah stasioner.

\section{Uji lag Optimal}

Setelah melakukan uji stasioneritas selanjutnya dilakukan uji lag optimal untuk menentukan panjang lag optimal yang akan digunakan dalam analisis VAR. Dalam memilih jumlah lag optimal, model VAR diestimasi dengan jumlah lag yang berbeda-beda kemudian dibandingkan nilai AICnya. Nilai AIC yang paling rendah dipilih sebagai lag optimal. Dari uji lag optimal diperoleh hasil dari bahwa seluruh saham optimal pada lag ke 6 .

\section{Uji Kausalitas Granger}

Uji kausalitas Granger digunakan untuk melihat ada atau tidaknya hubungan antara variabel-variabel makroekonomi (return faktor) dengan return saham. Untuk melihat ada atau tidaknya hubungan antar variabel dapat dilihat dari nilai probabilitasnyajika nilai probabilitas $<\alpha$ maka dapat dinyatakan terdapat hubungan kausalitas. Untuk melihat signifikansi antar variabel dapat dilihat dari nilai $\mathrm{F}$ hitungnya dengan cara membandingkan nilai $\mathrm{F}$ hitung dengan nilai $\mathrm{F}$ tabel jika $\mathrm{F}$ hitung $>\mathrm{F}$ tabel maka dapat dinyatakan hubungan kausalitasnya memiliki pengaruh yang signifikan.
Berdasarkan uji kausalitas Granger diperoleh hanya ada satu saham yang memiliki hubungan kausalitas dengan lebih dari satu variabel makro ekonomi yaitu LPKR dipengaruhi oleh inflasi dan kurs sedangkan Sembilan saham lainnya tidak mempunyai hubungan kausalitas yang diharapkan. Hasil uji kausalitas granger pada saham LPKR dapat dilihat pada Tabel berikut:

Tabel 3. Hasil Uji Kausalitas Granger

\begin{tabular}{|c|c|c|c|c|}
\hline No & Variabel 1 & Variabel 2 & F hitung & Prob. \\
\hline 1 & Inflasi & LPKR & 2.52317 & 0.04890 \\
\hline 2 & LPKR & Inflasi & 0.78472 & 0.59040 \\
\hline 3 & Kurs & LPKR & 2.70348 & 0.03770 \\
\hline 4 & LPKR & Kurs & 0.76820 & 0.60220 \\
\hline
\end{tabular}

Tabel 3 menjelaskan bagaimana pengaruh variabel 1 terhadap variabel 2 dengan melihat nilai probabilitas dan $\mathrm{F}$ hitungnya. Uji Kausalitas Granger dalam penelitian ini menggunakan nilai $\alpha$ yaitu $10 \%(0,1)$. Dari Tabel 3 terlihat bahwa uji kausalitas Granger inflasi terhadap LPKR memiliki nilai probabilitas yang lebih kecil dari nilai $\alpha$ yaitu $0,0489<0,1$ dan $\mathrm{F}$ hitungnya lebih besar dari $\mathrm{F}$ tabelnya yaitu $2,52317>2,09$. Sedangkan LPKR terhadap inflasi memiliki nilai probabilitas yang lebih besar dari nilai $\alpha$ yaitu $0,5904<0,1$ dan $\mathrm{F}$ hitungnya lebih kecil dari $\mathrm{F}$ tabel yaitu $0,78472<2,09$. Hal ini berarti terdapat pengaruh inflasi terhadap LPKR secara signifikan namun tidak terdapat pengaruh dari LPKR terhadap inflasi.Dengan interpretasi yang sama untuk Kurs terhadap LPKR dapat dinyatakan memiliki pengaruh yang signifikan sedangkan untuk LPKR terhadap kurs tidak memiliki pengaruh. Oleh karena itu dalam model VAR pada saham LPKR hanya menggunakan dua variabel makroekonomi yaitu Inflasi dan kurs.

\section{Uji Diagnostik Portmanteau}

Uji Portmanteau menghasilkan statistik Q yang dihitung menggunakan persamaan (8). Model VAR dikatakan whitenoise apabila nilai 
statistik-Q $>\alpha(0,1)$. Berikut adalah hasil uji Portmanteau dengan bantuan software EViews:

Tabel 4. Hasil Uji Portmanteau

\begin{tabular}{|c|c|c|}
\hline Lag & Q-Statistik & Probabilitas \\
\hline 1 & 1.983256 & NA* \\
\hline 2 & 8.556336 & NA* \\
\hline 3 & 11.68300 & NA* \\
\hline 4 & 19.52359 & NA* \\
\hline 5 & 26.62544 & NA* \\
\hline 6 & 30.51175 & NA* \\
\hline 7 & 41.11649 & 0.1034 \\
\hline 8 & 45.03679 & 0.1435 \\
\hline 9 & 52.84074 & 0.2136 \\
\hline 10 & 58.31440 & 0.2737 \\
\hline 11 & 62.92333 & 0.2859 \\
\hline 12 & 69.72689 & 0.2576 \\
\hline
\end{tabular}

Dari Tabel 4 diketahui nilai probabilitas statistik $\mathrm{Q}>0,1$ yang berarti tidak terdapat residual serial dalam model dan dapat dinyatakan memenuhi asumsi white noise.

\section{Model VAR}

Model VAR untuk saham LPKR adalah sebagai berikut:

$$
\begin{aligned}
\text { Inflasi }_{t}= & 0,909899+4,184681 \text { LPKR }_{t-1} \\
-0, & 921363 \text { LPKR }_{t-2}+9,418961 \text { LPKR }_{t-3} \\
& -16,60064 \text { LPR }_{t-4}+3,063556 \text { LPR }_{t-5} \\
& -16,57074 \text { LPKR }_{t-6}+0,05024 \text { Inflasi }_{t-1} \\
& +0,268486 \text { Inlflasi }_{t-2}-0,324887 \text { Inflasi }_{t-3} \\
& +0,479514 \text { Inflasi }_{t-4}+0,026263 \text { Inflasi }_{t-5} \\
& -0,299301 \text { Inflasi }_{t-6}+37,141926 \text { Kurs }_{t-1} \\
& -49,38605 \text { Kurs }_{t-2}+19,24208 \text { Kurs }_{t-3} \\
& -17,15496 \text { Kurs }_{t-4}+4,864203 \text { Kurs }_{t-5} \\
& -126,8621 \text { Kurs }_{t-6 .}
\end{aligned}
$$

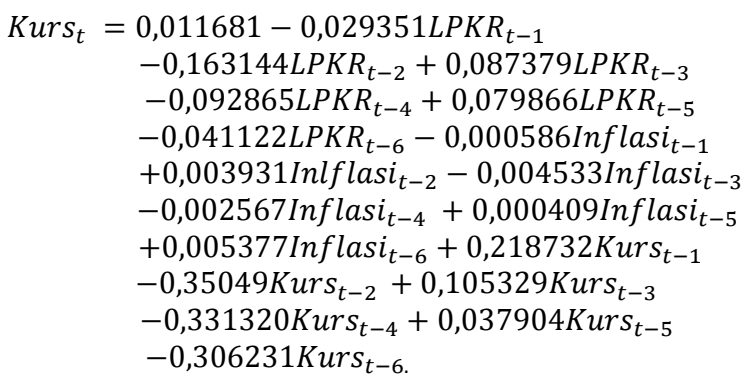

\begin{tabular}{|c|c|c|}
\hline No & Expected Return Variabel & $\begin{array}{l}\text { Rata- } \\
\text { Rata }\end{array}$ \\
\hline 1 & Inflasi & $-0,03171$ \\
\hline 2 & $\begin{array}{l}\begin{array}{l}\text { Nilai Tukar } \\
\text { (Kurs) }\end{array} \\
\end{array}$ & 0,00246 \\
\hline
\end{tabular}

Model VAR yang telah diperoleh dari langkah sebelumnya selanjutnya dilakukan estimasi untuk masing-masing variabel. Estimasi dari masing-masing variabel diperoleh dengan bantuan software EViews. Selanjutnya rata-rata expected return masing-masing variabel dapat dilihat pada tabel berikut :

Tabel 5. Expected Return Variabel

\section{Persamaan APT}

Expected return saham dalam penelitian ini mengunakan model APT. Dari langkahlangkah sebelumnya dapat disusun persamaan APT sebagai berikut:

$$
\begin{aligned}
\mathrm{E}\left(\mathrm{R}_{\text {LPKR }}\right)= & 0.0338 \times R_{F} \\
& +0.00165\left[\left(E\left(R_{\text {Inflasi }}\right)\right)-R_{F}\right] \\
- & 0.278\left[\left(E\left(R_{\text {Kurs }}\right)\right)-R_{F}\right] .
\end{aligned}
$$

Dari persamaan APT yang diperoleh kemudian dilakukan perhitungan Expected return saham LPKR sebesar 0,03340 atau 3,340\%.. Expected return saham LPKR lebih tinggi dari actual returnnya yaitu 0,02819 hal ini berarti return saham LPKR diperkirakan akan naik.

\section{Kesimpulan}

Berdasarkan uraian pada bab hasil dan pembahasan, maka diperoleh beberapa simpulan, yaitu:

1. Berdasarkan analisis Vector Autoregression (VAR) pada sepuluh saham Kompas100 hanya saham LPKR yang dipengaruhi oleh lebih dari satu variabel makroekonomi dalam penelitian ini. Saham LPKR dipengaruhi secara signifikan oleh inflasi dan kurs.

2. Berdasarkan model Arbitrage Pricing Theory (APT) diperoleh model untuk saham LPKR sebagai berikut: 


$$
\begin{aligned}
\mathrm{E}\left(\mathrm{R}_{\text {LPKR }}\right)= & 0.0338 \times R_{F} \\
& +0.00165\left[\left(E\left(R_{\text {Inflasi }}\right)\right)-R_{F}\right] \\
- & 0.278\left[\left(E\left(R_{\text {Kurs }}\right)\right)-R_{F}\right] .
\end{aligned}
$$

Expected return saham LPKR lebih tinggi dari actual returnnya. Hal ini menunjukkan bahwa estimasi return saham dengan model APT pada saham LPKR akan mengalami kenaikan.

\section{Daftar Pustaka}

Box, G.E.P., dan Pierce D.A. 1970.

"Distribution of residual autocorrelations in autoregressive-integrated moving average time series models".J Amer Statist Assoc, Vol 65:1509-25.

Fabozzi, F.J. 1999. Manajemen Investasi. Salemba Empat. Jakarta.

Gujarati, D. 2003. Basic Ekonometrics. Mc Graw-Hill, New York.

Makridakis, S., S.C Wheelwright. Dan V.E, McGee. 1999. Metode dan Aplikasi Peramalan. Erlangga. Jakarta.

Mankiw, N.G. 2007. Makroekonomi. Erlangga. Jakarta.

Rosadi, D. 2012. Ekonometrika dan Analisis Runtun Waktu Terapan. ANDI. Yogyakarta.

Sukirno, S. 2007. Pengantar Teori Makroekonomi. Kencana. Jakarta.

Tsay, R.S. 2002. Analysis Financial Time Series. John Willey and Sons Inc. United States of America.

Widarjono, A. 2007. Ekonometrika Teori dan Aplikasinya untuk Ekonomi dan Bisnis. Ekorisia. Yogyakarta.

Winarno, W.W. 2007. Analisis Ekonometrika dan Statistika dengan EViews. Unit Penerbit dan Percetakan AMP YKPN, Yogyakarta. 